\title{
The effects on lipophilicity of replacing oxygenated functionality with their fluorinated bioisosteres
}

\author{
Richard J. Glyn and Graham Pattison* \\ Chemistry Research and Enterprise Group, School of Pharmacy and Biomolecular Sciences, University of Brighton, \\ Lewes Road, Brighton, UK. BN2 4GJ. \\ KEYWORDS fluorine; bioisostere; lipophilicity; hydroxy; alkoxy; aromatic; hydrogen bonding
}

\begin{abstract}
The replacement of oxygenated functionality (hydroxy, alkoxy) with a fluorine atom is a very commonly used bioisosteric replacement in medicinal chemistry. In this paper we use a Molecular Matched Pair Analysis approach to better understand the effects of this bioisosteric replacement on the physicochemical properties of compounds, particularly in terms of lipophilicity. We observe that the presence of electron-donating groups on an aromatic ring generally increase the difference in lipophilicity between an oxygenated compound and its fluorinated analogue.
\end{abstract}

\section{Introduction}

During a lead optimization process, medicinal chemists routinely switch simple functional groups for alternatives to establish what effect these substitutions have on drug activity and properties. Some of these changes are known to have relatively little effect on biological activity on many occasions, and are known as bioisosteric replacements. ${ }^{1}$

One of the most important bioisosteric replacements that medicinal chemists make during a lead optimization program is the replacement of oxygenated functionality (often a hydroxy or methoxy group on an aromatic ring) with a fluorine atom.1, 2 Fluorine is one of the most important elements in drug design; its high electronegativity can be used to modulate parameters ranging from the binding of a drug to its target, to acidity and the charge state of a drug under physiological conditions. ${ }^{3-7}$

A key reason that chemists may choose to replace oxygenated functionality with a fluorine atom is in blocking unwanted metabolic processes. ${ }^{8}$ Electron-rich aromatic rings such as phenols and anisoles are particularly susceptible to oxidative metabolic processes. Replacement of these groups with a fluorine atom can block these processes. One example of this was seen during a study on the

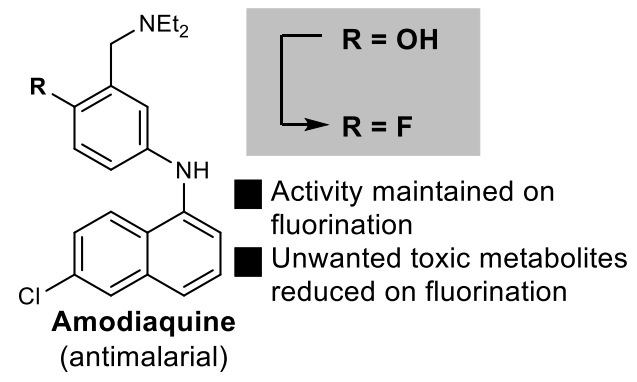

Scheme 1: Comparing the pharmaceutical behavior of hydroxy- and fluoro-substituted compounds optimization of the antimalarial amodiaquine (Scheme 1). ${ }^{9}$ The parent hydroxy compound (amodiaquine) was highly susceptible to metabolic oxidation processes, often forming toxic quinone byproducts. Replacement of hydroxy with fluorine prevented these metabolic processes, whilst maintaining similar activity $\left(\mathrm{IC}_{50}(\mathrm{OH})=20 \mathrm{nM}, \mathrm{IC}_{50}(\mathrm{~F})=\right.$ $40 \mathrm{nM}$ ).

However, the replacement of oxygenated functionality with a fluorine atom may lead to a change in the physicochemical properties of a molecule. In particular, fluorination can have a have a significant effect on the lipophilicity of a molecule. Lipophilicity plays a key role in drug design; not only does it play a key role in biodistribution of a drug, but is also of great importance to factors such as potency, metabolic clearance and toxicology. ${ }^{10-13}$

The effect of fluorination on lipophilicity is fairly complex and not always well-understood. In general, fluorination of an aromatic ring with either a single fluorine atom or a perfluoroalkyl group (e.g. $\mathrm{CF}_{3}$ group) leads to an increase in lipophilicity relative to hydrogen at the same position. However, evidence is also beginning to emerge that partial fluorination of alkyl groups can be used to successfully reduce lipophilicity. ${ }^{14-24}$

Alcohol- and ether-based functionality generally reduce the lipophilicity of a compound relative to a hydrogen at the same position. Therefore, the bioisosteric replacement of an aromatic hydroxy or methoxy group with a fluorine atom would therefore be expected to lead to an increase in lipophilicity. However, the magnitude of this increase is poorly understood, as is how other functional groups that are present in a molecule may affect this magnitude. As part of an interest in the chemistry of fluorinated aromatic compounds, ${ }^{25-31}$ in this paper we will describe how structural features in a drug-like molecule may affect the change in lipophilicity on transformation of an aromatic hydroxy or methoxy group to a fluorine atom. 


\section{Results and Discussion}

We chose to take a Molecular Matched Pairs Analysis (MMPA) approach to understanding this problem. ${ }^{32-35} \mathrm{Sev}$ eral databases (including the Reaxys, OCHEM and PhysProp databases) were searched for pairs of molecules where lipophilicity values were known for either both an $\mathrm{OH}$-containing and $\mathrm{F}$-containing aromatic ring, or an $\mathrm{OCH}_{3}-$ containing and F-containing aromatic ring, and the lipophilicity values and structures recorded. This data relied heavily on previous work by Hansch and Sangster among others, who determined accurate $\log \mathrm{P}$ values for a broad range of compounds. ${ }^{36-38}$ In addition, we determined, using an HPLC method, 19, 39, 40 log P values for a range of simple substituted aromatic systems where these were not available in the literature.

The OCHEM database showed 1287 examples of replacement of $\mathrm{OH}$ to $\mathrm{F}$, as well as 6574 examples of an $\mathrm{OCH}_{3}$ to $\mathrm{F}$ matched pair, showing that this is a common bioisosteric replacement. However, the majority of these pairs did not have lipophilicity data and our continuing analysis only includes those where log P data was available for both $\mathrm{O}$ and $\mathrm{F}$ compounds within a matched pair.

Figure 1 shows histograms representing the difference in $\log \mathrm{P}$ between a fluorinated aromatic compound and its hydroxylated or methoxylated matched pair. They show that for the sample of 127 matched pairs studied, 114 showed an increase in lipophilicity on conversion of a hydroxy group to a fluorine atom, with the mean increase being $0.58 \log \mathrm{P}$ units (Figure 1a). However, the change in

(a)

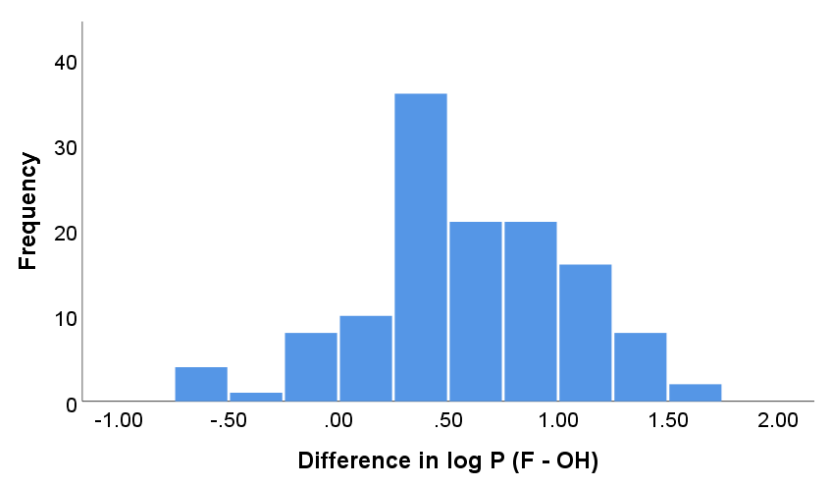

(b)

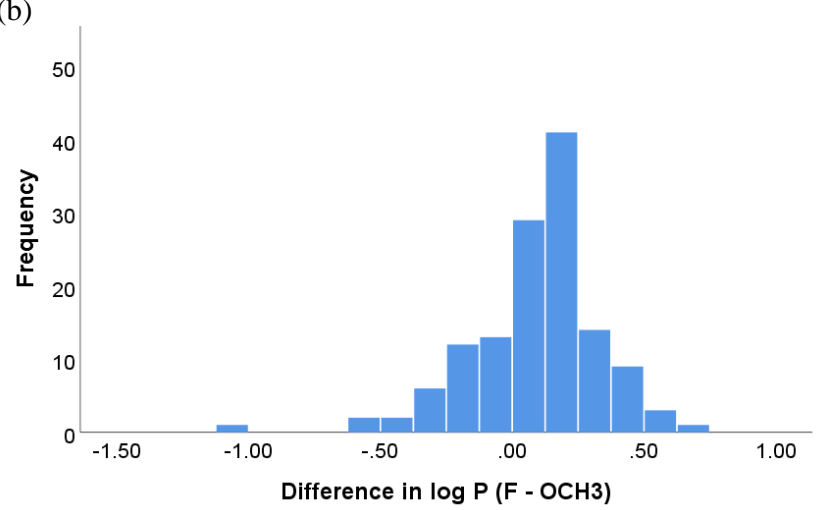

Figure 1: Histograms showing the difference in $\log \mathrm{P}$ between (a) F- OH matched pairs; (b) $\mathrm{F}-\mathrm{OCH}_{3}$ matched pairs $\log \mathrm{P}$ on conversion of a hydroxy group to a fluorine atom ranged from -0.74 to +1.70 , demonstrating the wide variability on the effect on lipophilicity upon this bioisosteric replacement, and indeed, 13 of the studied compounds in fact showed an unexpected decrease in log $\mathrm{P}$ on conversion from a hydroxyl group to a fluorine atom.

The situation was further nuanced when comparing a methoxy compound to its fluorinated matched pair (Figure $1 b)$. Of the 133 matched pairs studied, 97 showed an increase in $\log \mathrm{P}$ on fluorination, with a mean increase of $0.09 \log \mathrm{P}$ units. The change in $\log \mathrm{P}$ on conversion of a methoxy group to a fluorine atom ranged from -1.08 to +0.63 . The smaller increase in $\log P$ of methoxy compounds relative to hydroxy compounds is likely to be reflective of the increased lipophilicity of a methoxy group compared to a hydroxy group. 36 of our compounds showed a decrease in log $\mathrm{P}$ on transformation of a methoxy group to a fluorine atom, around $25 \%$ of the sample.

We then sought to better understand these observations, in particular why sometimes increases or decreases in log $P$ occurred within a matched pair, and why this magnitude differed. We first chose to analyze a series of simple disubstituted aromatic systems; matched pairs containing a fluorine atom and either a hydroxy or methoxy group, with another functional group at the ortho, meta or para position. The functional groups were chosen to cover a broad range of electron-withdrawing / donating, polar / nonpolar, and hydrophobic / hydrophilic functionality. Where lipophilicity data for a compound in our series was not available reliably in the literature we determined $\log \mathrm{P}$ values experimentally using an HPLC method (see Supporting Information). ${ }^{19,} 39,40$

The results of this analysis are shown in Figures 2 and 3. Figure 2 shows the difference in $\log P$ between a fluorinated and hydroxylated aromatic ring, bearing a range of substituents at the ortho, meta and para positions. These showed that, as expected, within a matched pair fluorination led to an increase in lipophilicity for the majority of functional groups. Interestingly however, a trend was observed in the kinds of functional group which lead to the largest increase in log P. Electron-donating groups such as $\mathrm{OH}, \mathrm{NH}_{2}, \mathrm{OMe}$ and $\mathrm{NHCOR}$ lead to the largest increases in $\Delta \log \mathrm{P}$ on replacement of a phenol with a fluorine atom, often around +0.75 to $+1.2 \log \mathrm{P}$ units. Acetylation of a nitrogen or oxygen substituent attenuated its effect slightly (compare e.g. $p$-OH 20-para $\Delta \log \mathrm{P}=+1.18$ to $p$-OAc 14para $\Delta \log \mathrm{P}=0.59$ ), with the effect being smaller for nitrogen than oxygen (e.g compare $p-\mathrm{NH}_{2}$ 19-para $\Delta \log \mathrm{P}=$ +1.11 to $p$-NHAc 18-para $\Delta \log \mathrm{P}=+1.01$ ). At the other end of the scale, electron-withdrawing groups such as carbonyl groups, and halogen atoms, lead to moderate increases in $\log \mathrm{P}(+0.2-+0.6 \log \mathrm{P}$ units), whilst stronger electron withdrawing groups including nitro, trifluoromethyl and cyano groups led to the smallest increases or even decreases in $\log \mathrm{P}$ on fluorination $(\Delta \log \mathrm{P}-0.1-+0.3)$.

Whilst meta- and para-substituted compounds generally showed similar results, some interesting differences were observed amongst the ortho-substituted compounds. In general, for ortho-substituted compounds, the difference in $\log \mathrm{P}$ between a fluorinated compound and its hydroxylated analogue was smaller for the large majority of 


\begin{tabular}{|c|c|c|c|c|}
\hline \multirow[t]{2}{*}{ Entry } & \multirow[t]{2}{*}{ Substituent } & \multicolumn{3}{|c|}{ Difference in $\log P(\mathrm{~F}-\mathrm{OH})$} \\
\hline & & Para & Meta & Ortho \\
\hline 1 & $\mathrm{NO}_{2}$ & -0.11 & -0.1 & -0.1 \\
\hline 2 & $\mathrm{CF}_{3}$ & 0.06 & 0.00 & 0.03 \\
\hline 3 & $\mathrm{C}(=\mathrm{O})-\mathrm{H}$ & 0.19 & 0.64 & 0.11 \\
\hline 4 & I & 0.29 & 0.35 & 0.42 \\
\hline 5 & $\mathrm{C}(=\mathrm{O})-\mathrm{OCH}_{3}$ & 0.32 & 0.45 & -0.73 \\
\hline 6 & $\mathrm{CN}$ & 0.30 & -0.23 & 0.32 \\
\hline 7 & $\mathbf{F}$ & 0.36 & 0.28 & 0.66 \\
\hline 8 & $\mathrm{C}(=0)-\mathrm{CH}_{3}$ & 0.37 & 0.38 & 0.11 \\
\hline 9 & $\mathrm{Cl}$ & 0.39 & 0.26 & 0.63 \\
\hline 10 & $\mathbf{P h}$ & 0.48 & 0.46 & 0.47 \\
\hline 11 & $\mathrm{C}(=0)-\mathrm{OH}$ & 0.49 & 0.65 & -0.49 \\
\hline 12 & $\mathrm{Br}$ & 0.49 & 0.29 & 0.54 \\
\hline 13 & $\mathrm{C}(=0)-\mathrm{NH}_{2}$ & 0.58 & 0.52 & -0.69 \\
\hline 14 & OAc & 0.59 & 0.51 & 0.31 \\
\hline 15 & $\mathrm{CH}_{3}$ & 0.64 & 0.79 & 0.87 \\
\hline 16 & $\mathbf{H}$ & 0.8 & 0.8 & 0.8 \\
\hline 17 & $\mathrm{O}-\mathrm{CH}_{3}$ & 0.85 & 1.02 & 0.82 \\
\hline 18 & NHAc & 1.01 & 0.92 & 0.31 \\
\hline 19 & $\mathrm{NH}_{2}$ & 1.11 & 1.09 & 0.64 \\
\hline 20 & $\mathrm{OH}$ & 1.18 & 1.13 & 0.83 \\
\hline
\end{tabular}
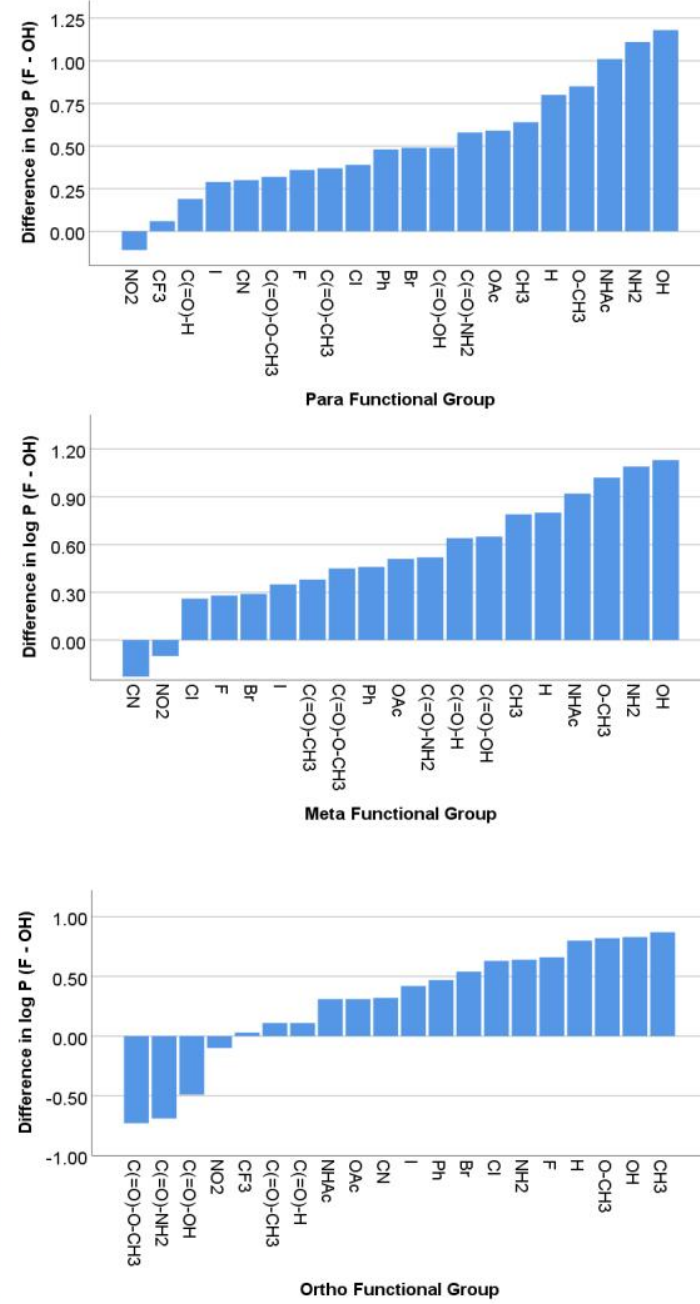

Figure 2: Differences in log P for fluoro and hydroxy compounds

substituents compared to a meta- or para-substituted compound. The range in $\Delta \log \mathrm{P}$ for ortho compounds was -0.7 to $+0.8 \log \mathrm{P}$ units, compared to -0.1 to $+1.2 \log \mathrm{P}$ units for meta- and para-substituted compounds. Compounds substituted with an ester, amide or carboxylic acid at the ortho position actually showed significant decreases in log $\mathrm{P}$ on fluorination, of generally around -0.7 to $-0.5 \log \mathrm{P}$ units.

We then repeated this analysis comparing fluorine- and methoxy-substituted molecular matched pairs (Figure 3). Whilst overall magnitudes of $\log \mathrm{P}$ changes were generally smaller within a matched pair for methoxy systems, a similar order of substituent effects was observed. Amine, alcohol and ether-based functionality showed the largest increases in $\log \mathrm{P}(\Delta \log \mathrm{P}$ approximately +0.25 to +0.5$)$, and carbonyl, nitro and halogen-based functional groups showed either a decrease or a very small increase in $\log \mathrm{P}$ on fluorination ( $\Delta \log \mathrm{P}$ approx. -0.25 to +0.2 in general).

This order of functional groups clearly suggested that electron-donating / withdrawing character of a distant functional group on an aromatic ring was playing a key role in the difference in $\log \mathrm{P}$ between fluorinated and oxygenated bioisosteres. To confirm this we plotted the difference in $\log \mathrm{P}$ against the Hammett $\sigma$-value of the substituent (Figure 4). This gave a moderate linear negative correlation showing that as $\sigma$-values became more negative, the difference in $\log \mathrm{P}$ increased. However, $\mathrm{r}^{2}$ values of only approximately 0.7 showed that these two variables were only moderately correlated, and that the situation was likely to be more complicated than a simple analysis of 


\begin{tabular}{|c|c|c|c|c|}
\hline \multirow{2}{*}{ Entry } & \multirow{2}{*}{ Substituent } & \multicolumn{3}{|c|}{ Difference in $\log \mathrm{P}\left(\mathrm{F}-\mathrm{OCH}_{3}\right)$} \\
\hline & & Para & Meta & Ortho \\
\hline 21 & $\mathrm{NO}_{2}$ & -0.23 & -0.26 & -0.04 \\
\hline 22 & $\mathrm{C}(=\mathrm{O})-\mathrm{H}$ & -0.22 & 0.22 & 0.20 \\
\hline 23 & $\mathbf{F}$ & -0.13 & -0.15 & 0.23 \\
\hline 24 & $\mathrm{CH}_{3}$ & -0.08 & 0.09 & 0.08 \\
\hline 25 & $\mathrm{CF}_{3}$ & -0.06 & 0.16 & 0.05 \\
\hline 26 & $\mathrm{C}(=\mathrm{O})-\mathrm{CH}_{3}$ & -0.02 & -0.07 & 0.20 \\
\hline 27 & $\mathrm{Cl}$ & 0.00 & -0.22 & 0.10 \\
\hline 28 & $\mathrm{C}(=\mathrm{O})-\mathrm{OCH}_{3}$ & 0.01 & 0.03 & -0.22 \\
\hline 29 & $\mathrm{Br}$ & 0.03 & -0.11 & 0.03 \\
\hline 30 & $\mathbf{I}$ & 0.04 & 0.10 & 0.17 \\
\hline 31 & $\mathrm{C}(=0)-\mathrm{NH}_{2}$ & 0.05 & 0.06 & -0.27 \\
\hline 32 & $\mathrm{C}(=0)-\mathrm{OH}$ & 0.11 & 0.13 & 0.18 \\
\hline 33 & $\mathbf{P h}$ & 0.15 & 0.21 & 0.18 \\
\hline 34 & $\mathbf{H}$ & 0.16 & 0.16 & 0.16 \\
\hline 35 & $\mathrm{NH}_{2}$ & 0.2 & 0.37 & 0.08 \\
\hline 36 & $\mathrm{CN}$ & 0.2 & -0.56 & 0.06 \\
\hline 37 & $\mathrm{O}-\mathrm{CH}_{3}$ & 0.22 & 0.15 & 0.54 \\
\hline 38 & $\mathrm{OH}$ & 0.36 & 0.59 & 0.39 \\
\hline 39 & $\mathrm{NHAc}$ & 0.44 & 0.35 & 0.36 \\
\hline 40 & OAc & 0.44 & 0.13 & 0.38 \\
\hline
\end{tabular}

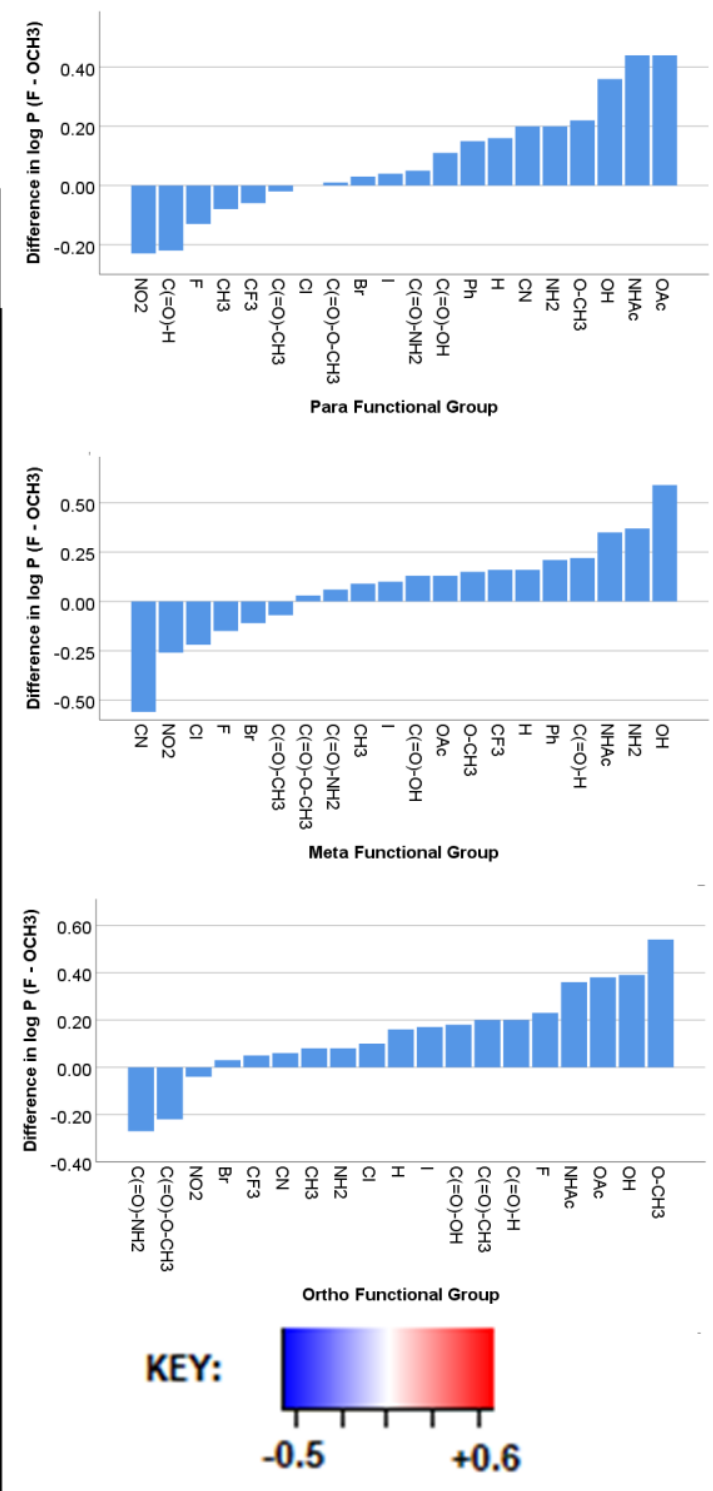

Figure 3: Differences in $\log P$ for fluoro and methoxy compounds

a)

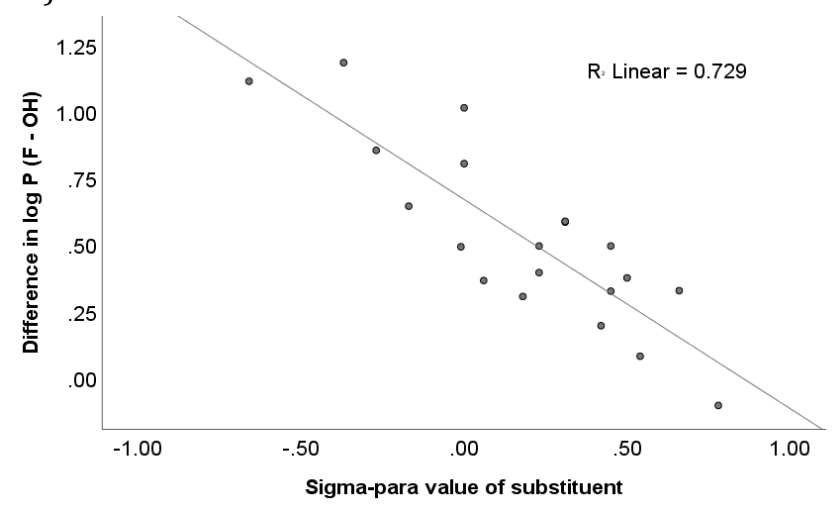

b)

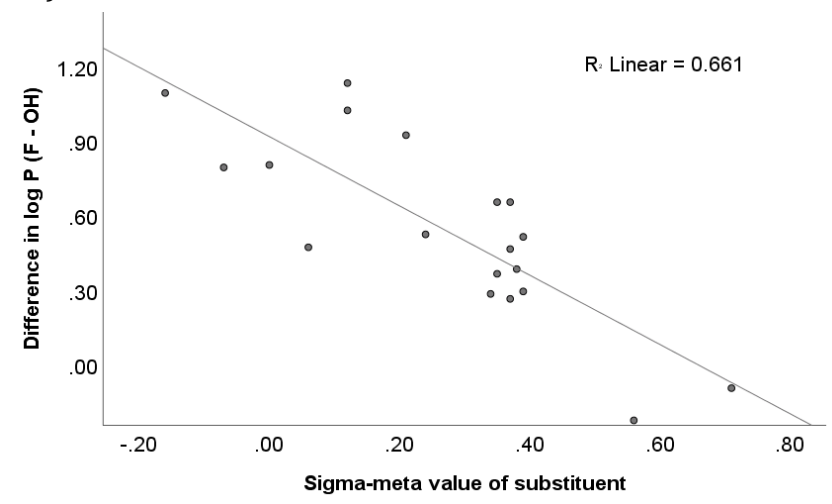

Figure 4: Plots of log P difference against substituent $\sigma$-values for a) para-and b) meta- substituents

electronic character of functional groups, with other parameters likely to be in play.
We decided that to gain further understanding of these results we should try to separate out the effects of fluori- 
nation and hydroxylation on an aromatic ring. We therefore performed an additional Molecular Matched Pair Analysis, comparing our disubstituted fluoro- / hydroxycompounds to their parent monosubstituted benzene (i.e. replacing $\mathrm{OH} / \mathrm{F}$ with $\mathrm{H}$ ).

In comparing fluoro- and hydroxy bioisosteres to their parent unsubstituted benzene (Figure 5) the obvious expected trend was initially observed, in that fluorination generally leads to an increase in log P relative to hydrogen at the same position, and hydroxylation leads to a decrease in log $\mathrm{P}$ relative to hydrogen. Interestingly, the decrease due to hydroxylation is normally larger than the increase due to fluorination. Electron-donating groups such as $\mathrm{OH}$, $\mathrm{NH}_{2}, \mathrm{OCH}_{3}$ show the largest decreases due to hydroxylation, but also simultaneously the largest increases due to fluorination. Electron-donating groups such as $\mathrm{CH}_{3}$ and $\mathrm{Ph}$ show a similarly large decrease due to hydroxylation, but interestingly, also often show a small decrease due to fluorination, making their net change from $\mathrm{F}$ to $\mathrm{OH}$ smaller. Carbonyl compounds generally show a moderate decrease on hydroxylation, and a moderate increase on fluorination. Halogen substituents give moderate decreases on hydroxylation, but little change on fluorination. Finally, stronger electron-withdrawing groups such as $\mathrm{NO}_{2}, \mathrm{CN}$ and $\mathrm{CF}_{3}$ groups show the smallest changes on both hydroxylation and fluorination; the sign of these changes can sometimes be reversed in that fluorination gives a decrease and hydroxylation an increase, sometimes leading to a small overall decrease in $\log \mathrm{P}$ on transformation from $\mathrm{OH}$ to $\mathrm{F}$.

Whilst these trends hold well for para- and metasubstituted benzenes, some additional trends were observed for ortho-substituted compounds. Carbonyl compounds show a moderate to large increase in log $\mathrm{P}$ on hydroxylation, which is compounded by a small decrease in $\log \mathrm{P}$ on fluorination for esters, amides and carboxylic acids to give an overall large increase in $\log \mathrm{P}$ on transformation of $\mathrm{F}$ to $\mathrm{OH}$. For aldehydes and ketones, fluorination leads to an increase in $\log \mathrm{P}$ making the overall change from transforming $\mathrm{OH}$ to $\mathrm{F}$ much smaller. In general, for the remaining functional groups, decreases on hydroxylation and increases upon fluorination are smaller for orthosubstituted compounds than for para- or meta-substituted compounds, leading to a smaller net change on transformation from $\mathrm{F}$ to $\mathrm{OH}$.

We believe that the key driver behind these observed trends is the hydrogen bond acceptor ability of the phenol. Aromatic fluorine is always a very weak hydrogen bond acceptor, so the difference in hydrogen bond acceptor capacity of a phenol and its matched fluoro pair will always be driven by how good a hydrogen bond acceptor the phenol is. Electron-donating groups will make a phenol a stronger hydrogen bond acceptor and decrease a phenol's relative lipophilicity compared to its fluorinated bioisostere, which is normally a weak acceptor, if at all. ${ }^{41-48}$

Of course, an electron-donating group would be expected to make a phenol a worse hydrogen bond donor. However, it would seem that this has little impact on its octanolwater $\log P$ value. This result has been previously supported by work by Abraham who showed that log $\mathrm{P}_{\text {oct }}$ was mainly influenced by hydrogen bond basicity as well as solute polarity and polarizability. ${ }^{49}$ Hydrogen bond acidity (a)

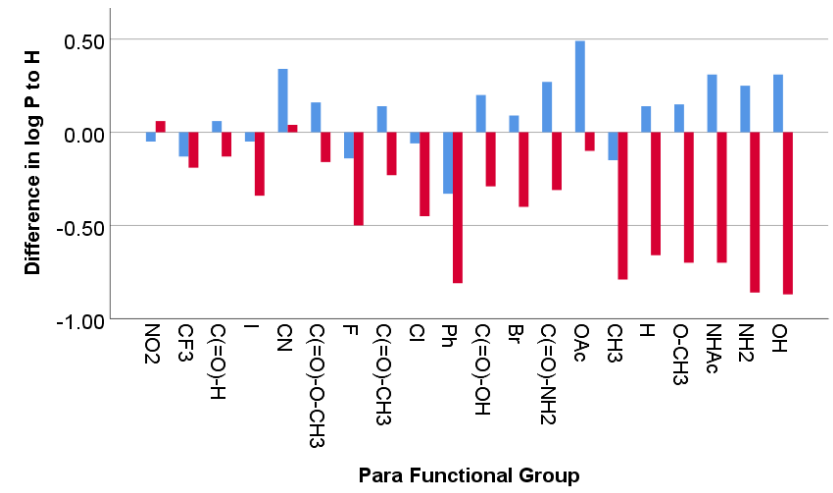

(b)

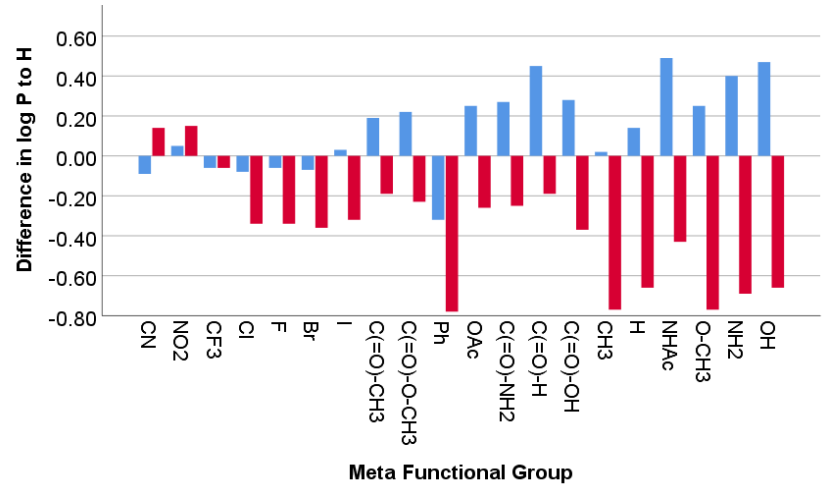

(c)

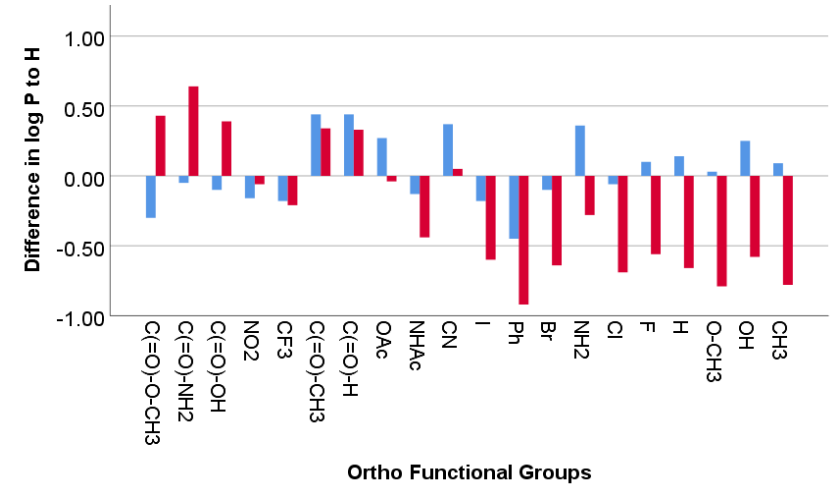

Figure 5: Matched Pair Analysis comparing fluoro / hydroxy compounds to parent benzenes for (a) para-; (b) meta-; (c) ortho-substituted systems

was only a factor in log $\mathrm{P}$ values determined in alkanewater mixtures.

Increase in $\log \mathrm{P}$ on fluorination is mainly driven by the very low polarizability of fluorine (related to its very high electronegativity). ${ }^{50}$ This increase is largest for oxygenand nitrogen-substituted aryl fluorides, and may be due to the electron-withdrawing effect of fluorine reducing the hydrogen bond acceptor capability of these basic functional groups. Carbonyl derivatives also seem to show moderate increases in log $\mathrm{P}$ on fluorination, which could also be due to reduced hydrogen bond acceptor character. Other substituents such as aryl, alkyl, halide, and nitro, which are unable to act effectively as hydrogen bond acceptors show a much smaller increase on fluorination. 
<smiles>[R]c1ccc([N+](=O)[O-])cc1[N+](=O)[O-]</smiles>

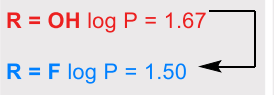
$\Delta \log \mathbf{P}=-0.17$

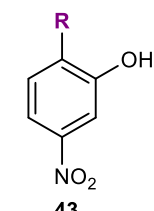

43 $\mathbf{R}=\mathbf{F} \log P=1.91$ $\Delta \log \mathbf{P}=+0.86$
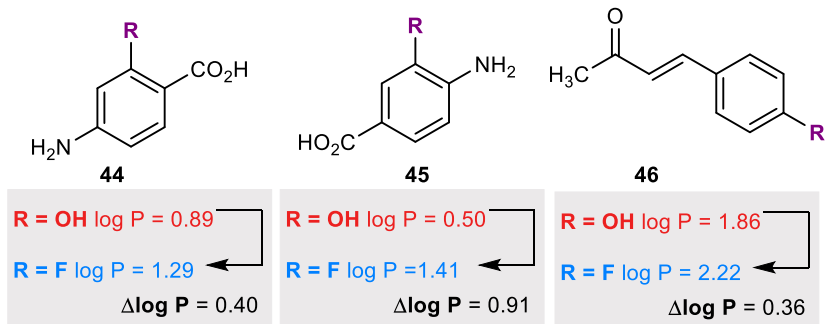

46
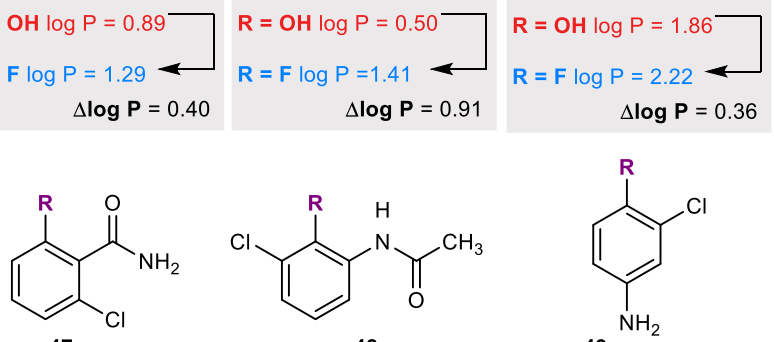

47

48

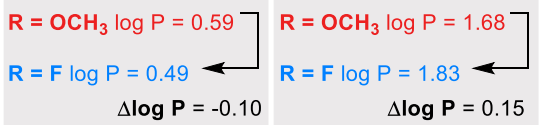

$\Delta \log P=-0.10$

$\Delta \log P=0.15$
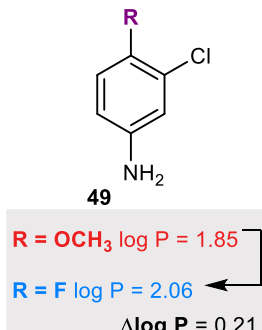

Figure 6: Multi-substituted systems

In general, the difference in log P for a phenol / fluorinated matched pair is smaller for ortho-substituted systems. Figure $5 \mathrm{c}$ would seem to suggest that this is mainly being driven by a smaller increase in $\log \mathrm{P}$ on fluorination, as decreases in $\log \mathrm{P}$ on hydroxylation are often similar. This may be due in general due to an increase in the dipole moment of the ortho-fluorinated system increasing their water solubility. Indeed, the log P of ortho-substituted aryl fluorides are generally lower than their meta- and parasubstituted isomers.

Ortho-substituted carbonyl compounds show unusual log $\mathrm{P}$ behavior, showing a decrease in $\log \mathrm{P}$ on conversion of $\mathrm{a}$ hydroxyl group to a fluorine atom. This is due to the formation of a particularly strong intramolecular hydrogen bond between the phenolic $0-\mathrm{H}$ (donor) and carbonyl oxygen (acceptor). This increases the log $\mathrm{P}$ of the phenol considerably as the six-membered hydrogen-bonded complex is stabilized by resonance, which reduces its polarizability. ${ }^{51,52}$

We then performed a similar matched-pair analysis on a series of phenols / aryl fluorides with two additional substituents to examine how the effects of multiple functional groups would compete against each other (Figure 6). Dinitro substituted system $\mathbf{4 1}$ showed a greater decrease in $\log \mathrm{P}$ on fluorination than the mono-nitrated system $(\Delta \log$ $\mathrm{P}-0.1741$ vs. -0.11 1-para), perhaps due to a further increased dipole moment. Similarly, nitration decreases the $\log \mathrm{P}$ difference between a para-fluoro substituted system $42(\Delta \log \mathrm{P}-0.0242$ vs. +0.36 7-para), although it had little effect on an ortho-hydroxy system $43(\Delta \log \mathrm{P}+0.8643$ vs. 0.83 20-ortho).
Comparison of compounds 44 and 45 demonstrates further the effects of an ortho-carbonyl group. Compound 44, with an ortho-carboxylic acid, shows a much smaller difference in $\log \mathrm{P}$ than compound $\mathbf{4 5}$ in which the carbonyl group is not ortho to the phenol / fluoro substituent $(\Delta \log$ $\mathrm{P}+0.4044$ vs. +0.9145 ), again likely due to intramolecular hydrogen bonding. Compound 46 demonstrates that conjugation of a carbonyl group to an aromatic ring through an alkene leads to a similar effect as a non- $\pi$-extended ketone substituent $(\Delta \log \mathrm{P}+0.3646$ vs +0.37 8-para), further supporting that this effect is electronic in nature. Compounds 47-49 show how an electron-withdrawing chlorine substituent can modulate the effect of amide and amine substituents. Chlorination decreases the effect of an ortho-amide substituent through reducing the strength of an intramolecular hydrogen bond $(\Delta \log \mathrm{P}-0.1047$ vs -0.27 31-ortho). It also modulates the effect of an electrondonating nitrogen substituent $(\Delta \log \mathrm{P}+0.1548$ vs +0.36 39-ortho), although showed much less effect on a paraamino substituent $(\Delta \log \mathrm{P}+0.2149$ vs +0.2035 -para)

We then wanted to see whether these rules applied to a broader series of more complex drug-like molecules (Figure 7). We found in the patent literature a series of thiazolyl-pyrimidine compounds bearing $\mathrm{OH}$ / $\mathrm{F}$ matched pairs on an aromatic ring, which had been developed during the lead optimization of a fungicide. ${ }^{53}$ These compounds all had an experimentally measured log $\mathrm{P}$ value. All of these compounds had an amine substituent para to the $\mathrm{OH} / \mathrm{F}$ group. For the 9 compounds 50-58 the difference in $\log \mathrm{P}$ between the $\mathrm{OH}$ and $\mathrm{F}$ analogues ranged from +0.60 to $+1.70 \log \mathrm{P}$ units. The mean increase was in line with what we observed for the para-amino system 19-para $(+1.11$ $\log \mathrm{P}$ units), however the range we observed was unexpected given that all the phenols would be expected to be electronically very similar.

We believe that two key factors are playing a role in this range of $\log \mathrm{P}$ differences. Firstly, the overall contribution that the phenol makes to hydrogen bonding in the molecule is critical. Compounds $\mathbf{5 0}$ and $\mathbf{5 1}$ have an additional contribution to hydrogen bonding from a pendent sidechain containing amine and ether groups. This makes the overall contribution of the phenol to hydrogen bonding in 50/51 less important than in compounds 56-58 which have no functionality capable of hydrogen-bonding in their side chains. This both makes the phenol in 50/51 less important to overall solubility, and also makes their fluorinated matched pair more water soluble than might otherwise be predicted as fluorine's non-polarizability can be compensated for by a hydrogen bonding substituent elsewhere in the molecule.

Furthermore, the inclusion of additional functionality of low polarizability would appear to increase the log $\mathrm{P}$ of the fluoro compound disproportionately compared to the phenol. Compare for example compounds 56 and 58, where the less polarizable cyclopropyl group in $\mathbf{5 8}$ gives a larger difference in $\log \mathrm{P}$ on fluorination compared to an iso-propyl group in $\mathbf{5 6}$.

It would therefore seem that increasing molecular size, whilst increasing the number of hydrogen-bonding groups across the whole molecule will decrease the difference in $\log \mathrm{P}$ compared to a simple aromatic system, whilst 

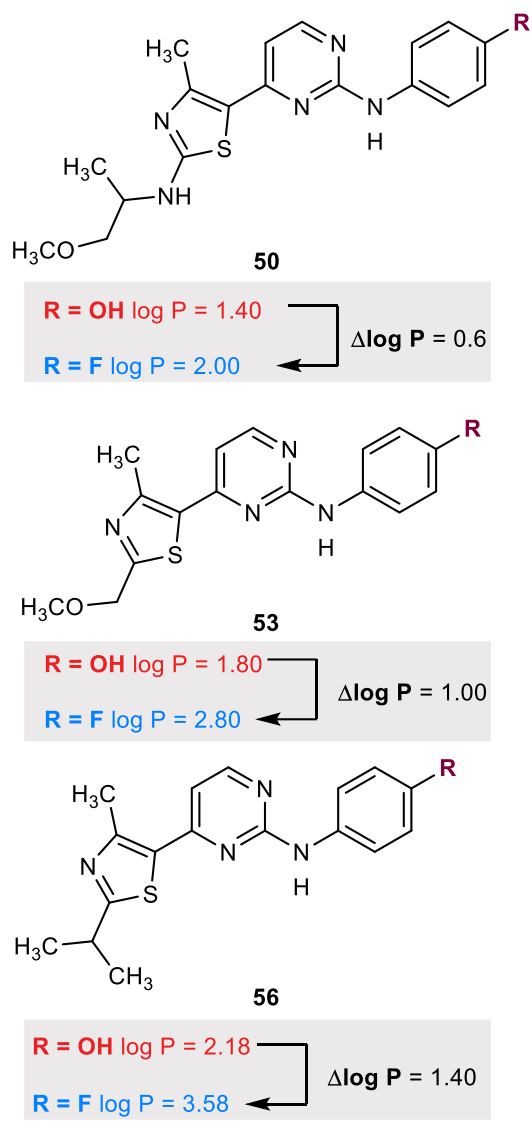
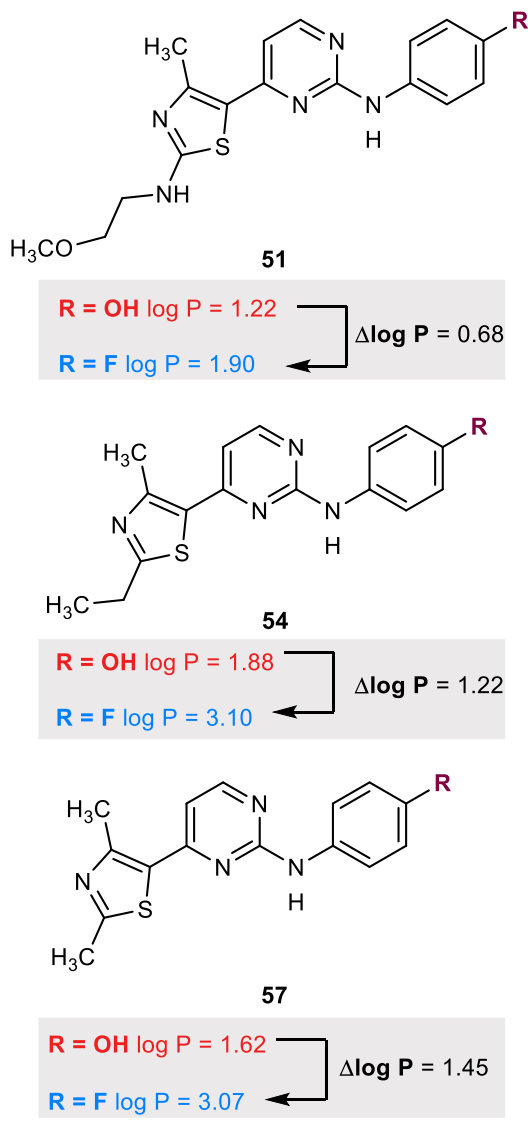
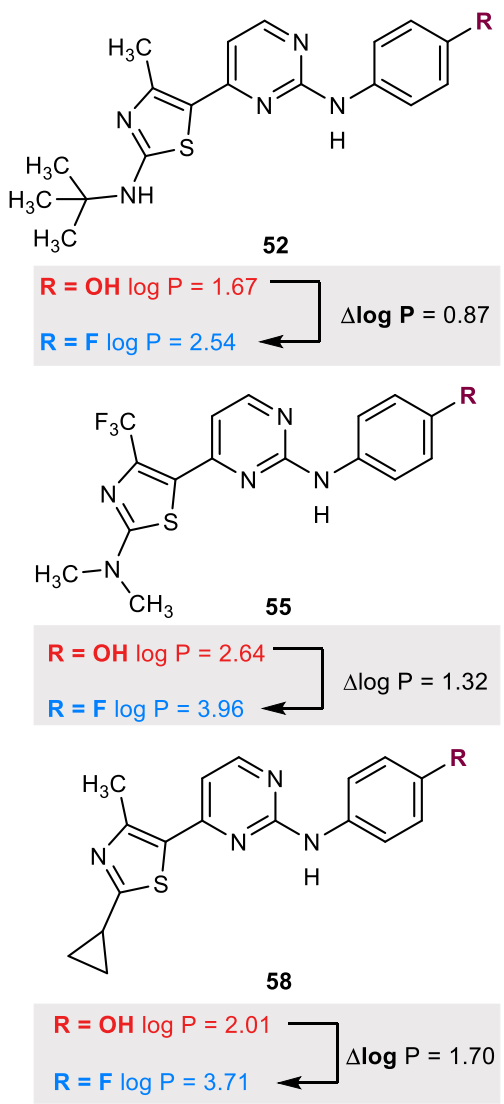

Figure 7: $\log \mathrm{P}$ data for matched $\mathrm{F} / \mathrm{OH}$ pairs in thiazolyl-pyrimidine fungicide molecules

increasing molecular size by the introduction of non-polar groups of low polarizability will increase the difference in $\log \mathrm{P}$ between a phenol and aryl fluoride.

We then examined how well the $\Delta \log \mathrm{P}$ rules we had established applied to other complex drug-like molecules for which lipophilicity data of matched $\mathrm{OH} / \mathrm{F}$ pairs was available in the literature (Figure 8). Aryl-thiazolones 59 showed a relatively small $\log \mathrm{P}$ difference of $+0.33 \log \mathrm{P}$ units, to be expected as the phenol is conjugated to an electron-withdrawing carbonyl-containing thiazolone unit. ${ }^{54}$ Similarly, potential anticonvulsant $\mathbf{6 0}$ bearing an electronwithdrawing imine unit had a moderate $\log \mathrm{P}$ difference of $+0.44 .{ }^{55}$ On the other hand, dual $\mathrm{D}_{2}$-receptor $/ \beta_{2}$ adrenoceptor agonists for the treatment of chronic obstructive pulmonary disease $\mathbf{6 1}$ gave a larger log $\mathrm{P}$ difference of $+0.76 \log P$ units between the phenol and aryl fluoride as these substituents are on an aromatic ring bearing an electron-donating alkyl substituent. ${ }^{56}$

When comparing methoxy substituents to fluoro in more complex systems, benzodiazepine $\mathbf{6 2}$ showed a $\log \mathrm{P}$ difference of $+0.07 \log P$ units, relatively small due to conjugation to a $\mathrm{C}=\mathrm{N}$ unit in the benzodiazepine ring. ${ }^{57}$ Derivative 63 bearing a more strongly electron-withdrawing amide substituent showed a negative change in log P on transformation from $\mathrm{OCH}_{3}$ to $\mathrm{F}$ of $-0.22 \log \mathrm{P}$ units. ${ }^{58}$ Oxazolylpiperidine compounds $\mathbf{6 4}$ gave a much larger log $\mathrm{P}$ difference of $+0.32 \log \mathrm{P}$ units due to the presence of a paraamine substituent on the aromatic ring. 59

Finally, we chose to examine log $\mathrm{P}$ differences of some heterocyclic derivatives (Figure 9). Pyridine derivatives showed some very interesting trends. For 2-substituted pyridines 65 the fluoro-compound was significantly more lipophilic than the hydroxy-compound $(\Delta \log P+1.42)$, yet this was reversed between 2-methoxy and 2fluoropyridine with the methoxy compound being more lipophilic $(\Delta \log \mathrm{P}-0.50)$. This trend was further exacerbated in the 4-substituted pyridine derivatives 67 , which showed an even larger increase on transformation of the hydroxy-compound to the fluoro-compound $(\Delta \log P$ +2.30 ), but a decrease on fluorination of the methoxy compound $(\Delta \log \mathrm{P}-0.82)$. However, these differences were nowhere near as pronounced for the 3-substituted pyridines 66, ( $\mathrm{F}-\mathrm{OH} \Delta \log \mathrm{P}=+0.29 \log \mathrm{P}$ units, $\mathrm{F}-\mathrm{OCH}_{3} \Delta \log$ $\mathrm{P}=-0.22$ ). It seems likely that these differences are being controlled by the ability of 2- and 4-hydroxypyridines to exist as a pyridone tautomer, which have significantly lower $\log \mathrm{P}$ values (compare 2-hydroxypyridine 65-0H $\Delta \log \mathrm{P}$ $=-0.58$ to 3 -hydroxypyridine $66-0 \mathrm{H} \Delta \log \mathrm{P}=+0.48$ ). The formation of a pyridone tautomer is not possible for methoxy- or 3-substituted systems. This reduced lipophilicity of pyridone tautomers was previously observed in work by Altomare. ${ }^{60}$

Pyrimidine 68 showed a large increase in $\log \mathrm{P}$ on fluorination of the hydroxy compound, but a small decrease on fluorination of the methoxy compound. Similarly to $\mathbf{6 5}$ and 67 this compound can form a pyrimidone tautomer. On the other hand, 8-substituted quinoline $\mathbf{6 9}$, which is fluorinated / oxygenated on the benzenoid ring and cannot form pyridone-like tautomers shows only a small increase in lipophilicity on fluorination. Indole $\mathbf{7 0}$, which is a more 

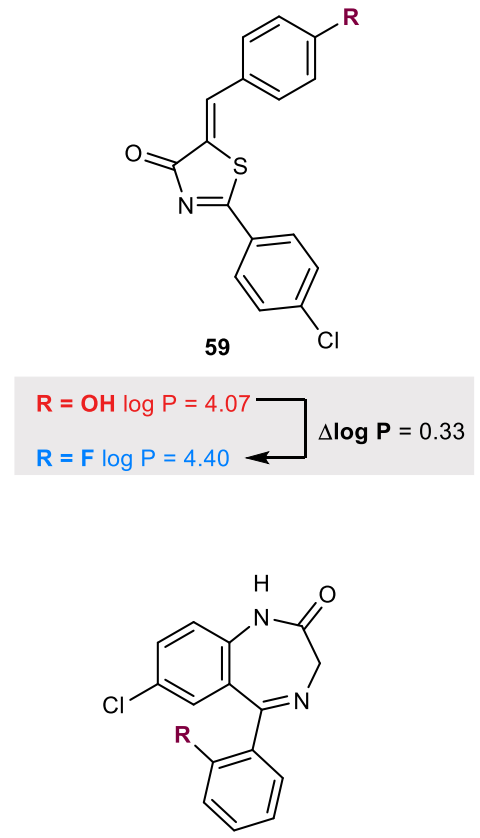

62

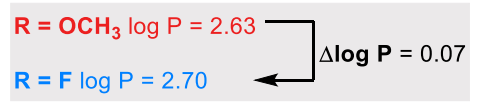

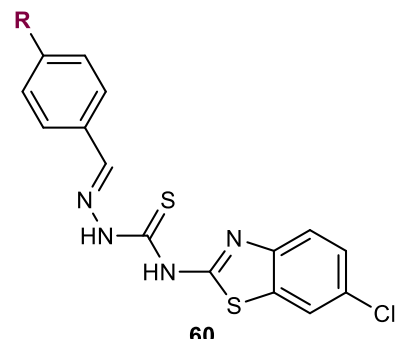

60
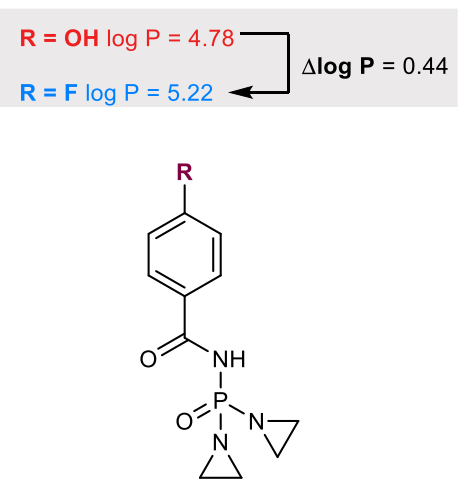

63

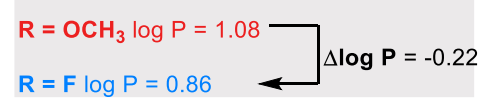<smiles>[R]c1ccc(CCOCCCS(=O)(=O)CCNCCc2ccc(O)c3[nH]c(=O)sc23)cc1</smiles>

61

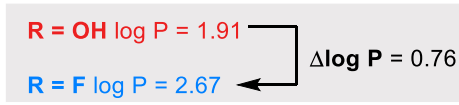

64

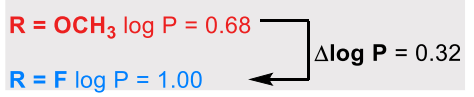

Figure 8: $\log \mathrm{P}$ data for matched $\mathrm{F} / \mathrm{OH}$ and $\mathrm{F} / \mathrm{OCH}_{3}$ pairs in assorted drug-like molecules<smiles>[R]c1ccccn1</smiles>

65

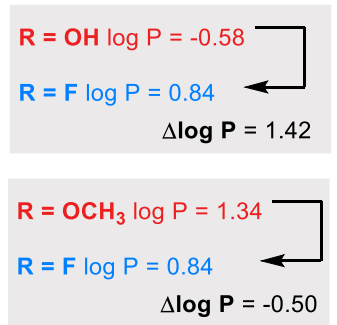<smiles>[R]c1cccnc1</smiles>

66

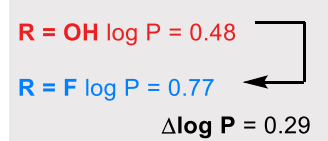

$\mathbf{R}=\mathrm{OCH}_{3} \log \mathrm{P}=0.99$

$\mathbf{R}=\mathbf{F} \log P=0.77$

$\Delta \log P=-0.22$<smiles>[R]c1ccncc1</smiles>

67

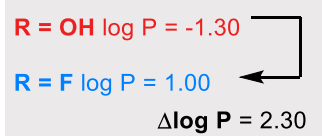

$\mathbf{R}=\mathbf{O C H}_{3} \log \mathrm{P}=1.82$

$\mathbf{R}=\mathbf{F} \log P=1.00$

$\Delta \log \mathrm{P}=-0.82$

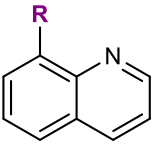

69

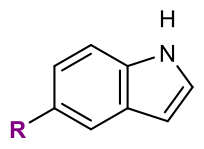

70

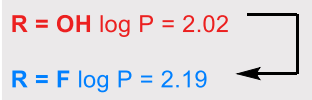

$\Delta \log \mathbf{P}=0.17$
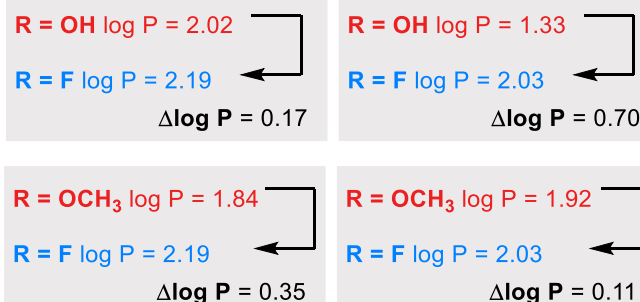

$\Delta \log \mathbf{P}=0.70$

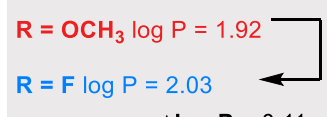

$\Delta \log \mathrm{P}=0.11$

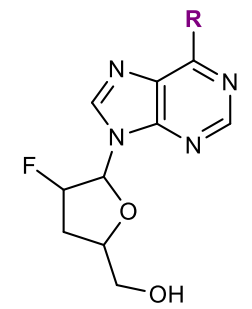

71

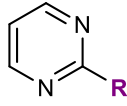

68
$\mathbf{R}=\mathbf{F} \log P=0.02 \longleftrightarrow$

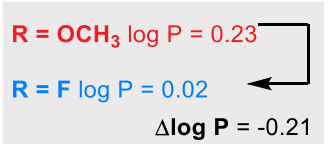

72

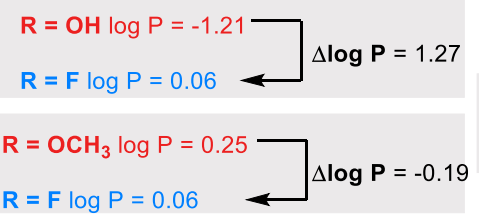

Figure 9: $\log \mathrm{P}$ data for matched $\mathrm{F} / \mathrm{OH}$ and $\mathrm{F} / \mathrm{OCH}_{3}$ pairs in heterocyclic molecules 
electron-rich ring system than quinoline 69 shows a larger increase in $\log \mathrm{P}$ on fluorination, perhaps reflecting a larger hydrogen-bond acceptor capability of the phenol than in the less-electron-rich quinoline 69.

These rules are again transferable to more complex molecules. Purine-based system 71 shows a large increase in $\log \mathrm{P}$ on transformation from $\mathrm{OH}$ to $\mathrm{F}(\Delta \log \mathrm{P}+1.27)$, reflective of an ability to form a pyridone-like tautomer. On the other hand, this compound shows a small decrease in $\log \mathrm{P}$ on transformation from $\mathrm{OCH}_{3}$ to $\mathrm{F}$, perhaps due to the electron-deficient nature of this ring system. Pyrimidine 72, which is fluorinated / hydroxylated on the benzenoid ring, shows a much smaller difference in log $\mathrm{P}$ between its $\mathrm{OH}$ and $\mathrm{F}$ analogues $(\Delta \log \mathrm{P}+0.15)$.

Our results had suggested that as well as hydrogen bond acceptor capability, polarizability was playing some role in the difference in log $\mathrm{P}$ between fluorinated and oxygenated bioisosteres. To better understand this effect, we decided to perform a further matched pair analysis looking at refractive index. The refractive index of a molecule is strongly linked to its polarizability. ${ }^{61}$ We chose to compare metasubstituted aryl fluorides to meta-anisoles (more refractive index data is available in the literature for anisoles, which are often liquid, compared to phenols, which are often solid) (Figure 10).

This matched pair analysis showed a clear trend in difference in refractive index based on the polarizability of the ancillary functional group in the molecule (Figure 10a). Non-polarizable functional groups such as fluorine atoms, trifluoromethyl and methyl substituents gave the largest decrease in refractive index on transformation of a methoxy substituent to a fluorine atom, whilst highly polarizable large substituents such as iodine atoms or bulky branched alkyl substituents gave the smallest decrease.

Comparison of the effects of fluorination and methoxylation to the parent hydrogen-substituted system (Figure $10 \mathrm{~b})$ showed that the decrease in refractive index on fluorination ( -0.017 to -0.038 refractive index units) was normally larger than the increase in refractive index on methoxylation $(-0.008$ to +0.029 refractive index units). Substituents with the lowest polarizability $\left(\mathrm{CF}_{3}, \mathrm{~F}, \mathrm{H}, \mathrm{CH}_{3}\right)$ show the largest increase in refractive index on methoxylation, whilst more polarizable substituents $\left(\mathrm{I}, \mathrm{Br}, \mathrm{OH}, \mathrm{NH}_{2}\right.$ ) may actually show small decreases in refractive index on methoxylation. Polarizable substituents (I, $\mathrm{Br}, \mathrm{OH}, \mathrm{NH}_{2}$ ) tend to show the largest decreases in refractive index on fluorination. This demonstrates how fluorination can reduce the effect of a polarizable substituent elsewhere in a molecule, but the effects of polarizable substituents may also reduce the effect of a methoxy group on a molecule's overall polarizability.

On these disubstituted rings it seems that the largest driving force on the difference in refractive index between a methoxy and fluoro-bioisostere is the methoxy group's contribution to increasing overall polarizability in the presence of non-polarizable groups, and how the effect of the methoxy substituent can be reduced in the presence of polarizable substituents. In future it will be of interest to perform a similar analysis on larger, more complex molecules such as those in Figure 7 where polarizable / non- a)

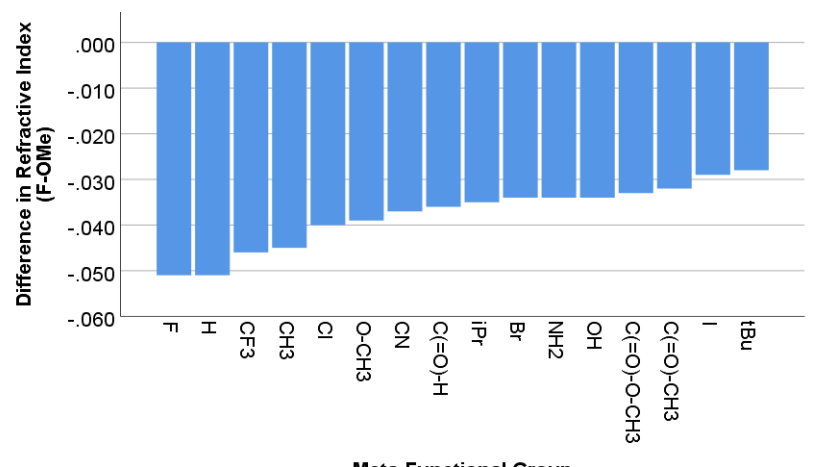

b)

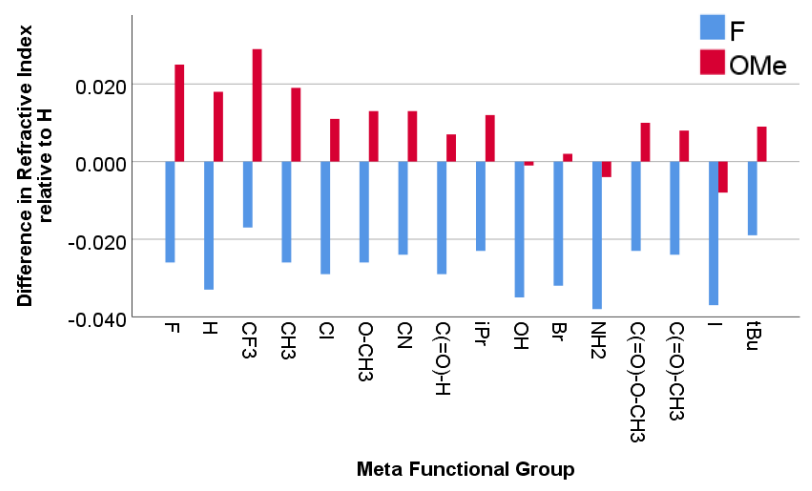

Figure 10: (a) Matched pair analysis of refractive index of meta-substituted aryl fluorides and anisoles. (b) Comparing the refractive index of aryl fluorides and anisoles to their parent $\mathrm{H}$-substituted arene

polarizable substituents are more remote to the fluorine / methoxy group.

We finally looked to determine the accuracy of various $\log \mathrm{P}$ calculators in assessing $\log \mathrm{P}$ differences between oxygen and fluorinated bioisosteres. Several calculators, including ChemDraw, clog $\mathrm{P}$, milog $\mathrm{P}$ and xlog $\mathrm{P}$ did not take account of functionality when calculating the difference in $\log \mathrm{P}$ between a phenol and an aryl fluoride, and gave a constant result for the difference. The Alog $\mathrm{P}$ calculator however, ${ }^{62-64}$ did give different results for the $\Delta \log \mathrm{P}$ between an oxygen and fluorinated matched pair depending on functionality elsewhere in the molecule, so became our focus for further analysis (Figure 11). To determine whether this calculator is likely to be useful for estimating the effect of an oxygen / fluorine replacement on log P we compared the results for our disubstituted systems highlighted in figure 2 to calculated values. However, whilst a plot of experimental $\log \mathrm{P}$ against calculated Alog $\mathrm{P}$ gave a reasonably good correlation for both phenols and aryl fluorides, a plot of experimental and calculated $\Delta \log \mathrm{P}$ values gave almost no correlation (Figure 11c). This would suggest that the majority of commonly-used log P calculators cannot be relied upon to accurately predict the difference between oxygen and fluorinated bioisosteres. 


\section{Conclusion}

We have compared the lipophilicities of substituted phenols and anisoles with their corresponding aryl fluorides, using a Molecular Matched Pair Analysis. This is a common bioisosteric replacement used during drug design. Our analysis has revealed several factors which appear to be important in the difference in $\log \mathrm{P}$ between an oxygen and fluorinated bioisostere.

Perhaps most important is the electronic character of any other substituents on the ring. Electron-donating substituents increase the hydrogen bond acceptor capability of a phenol, whilst having a much smaller effect on intermolecular forces in aryl fluorides. This leads to a large in crease in $\log \mathrm{P}$ on fluorination of electron-rich systems.

a)

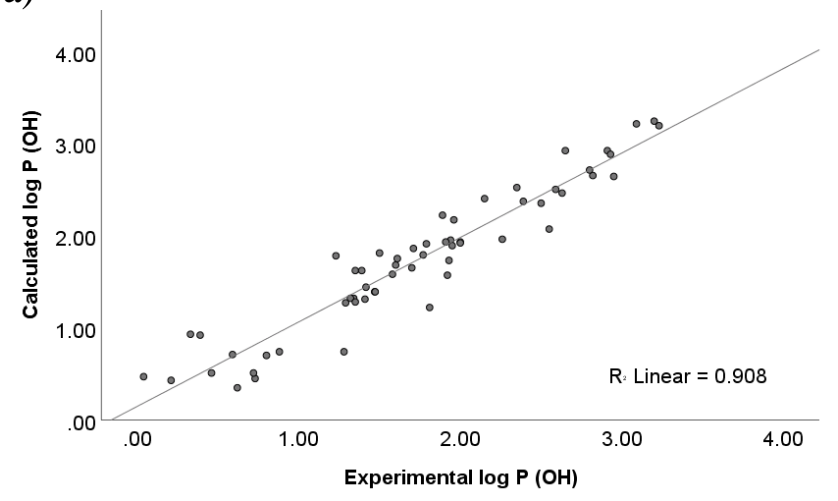

b)

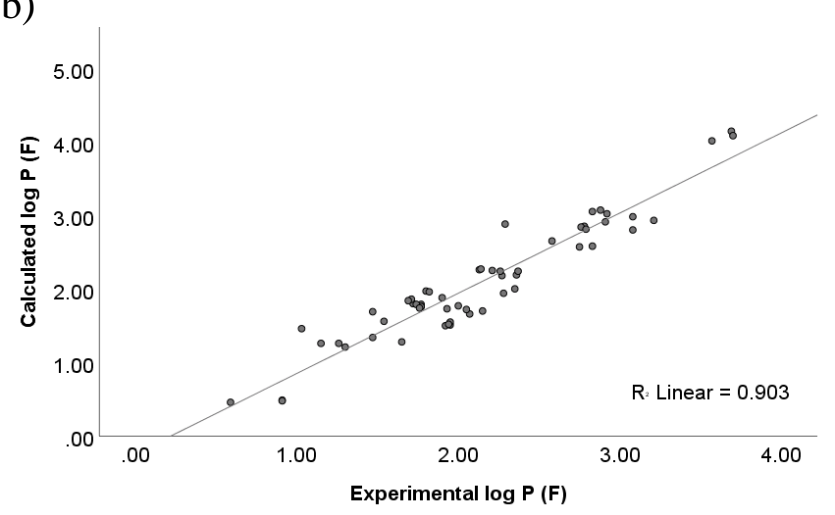

c)

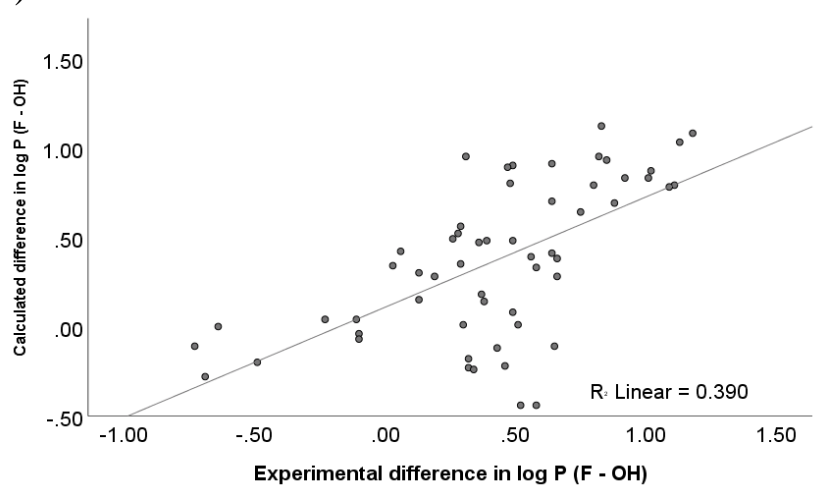

Figure 11: Comparing experimental and calculated $\log \mathrm{P}$ values for a) phenols; b) aryl fluorides; c) difference between $\mathrm{F}$ $\mathrm{OH}$
On the other hand, electron-withdrawing substituents weaken phenols as hydrogen bond acceptors, whilst simultaneously increasing water solubility of aryl fluorides through increasing dipole moments. This gives a much smaller increase in $\log \mathrm{P}$ on fluorination of electron-poor systems, or even a decrease in some cases.

The ability to participate in intramolecular hydrogen bonding is also a key factor in determining $\log \mathrm{P}$ differences between oxygen and fluorine bioisosteres. Phenols which can act as an intramolecular hydrogen bond donor, particularly where a carbonyl group acts as acceptor, show anomalously high lipophilicity, making these compounds often more lipophilic than their fluorinated matched pair.

In more complex molecules, the presence of additional hydrogen bond acceptor sites reduce the net importance of the phenol / fluoro substituent to overall solubility of the molecule and reduce the difference in log $\mathrm{P}$ between oxygen and fluorine bioisosteres. On the other hand, the inclusion of groups of low polarizability disproportionately decrease the water solubility of a fluorinated compound in a $\mathrm{O} / \mathrm{F}$ matched pair and increase the $\log \mathrm{P}$ difference between them.

This work has set out a series of empirical rules which affect the difference in lipophilicity between oxygen and fluorinated bioisosteres. We hope that it will be useful in rational drug design when this common bioisosteric replacement is made during a drug discovery program.

\section{ASSOCIATED CONTENT}

Supporting Information. Details on log P determination using HPLC.

\section{AUTHOR INFORMATION}

\section{Corresponding Author}

* Graham Pattison - Chemistry Research and Enterprise Group, School of Pharmacy and Biomolecular Sciences, University of Brighton, Lewes Road, Brighton, UK. BN2 4GJ. Email: g.pattison@brighton.ac.uk

\section{Author Contributions}

The manuscript was written through contributions of all authors.

\section{ACKNOWLEDGMENT}

We thank the University of Brighton for funding of consumables towards the MRes project of R.J.G.

\section{REFERENCES}

1. Meanwell, N. A., Synopsis of Some Recent Tactical Application of Bioisosteres in Drug Design. J. Med. Chem. 2011, 54, 2529-2591.

2. Meanwell, N. A., Fluorine and Fluorinated Motifs in the Design and Application of Bioisosteres for Drug Design. J. Med. Chem. 2018, 61, 5822-5880.

3. Gillis, E. P.; Eastman, K. J.; Hill, M. D.; Donnelly, D. J.; Meanwell, N. A., Applications of Fluorine in Medicinal Chemistry. J. Med. Chem. 2015, 58, 8315-8359.

4. Müller, K.; Faeh, C.; Diederich, F., Fluorine in Pharmaceuticals: Looking Beyond Intuition. Science 2007, 317, 1881. 
5. Purser, S.; Moore, P. R.; Swallow, S.; Gouverneur, V., Fluorine in medicinal chemistry. Chem. Soc. Rev. 2008, 37, 320-330.

6. Inoue, M.; Sumii, Y.; Shibata, N., Contribution of Organofluorine Compounds to Pharmaceuticals. ACS Omega 2020, 5, 10633-10640.

7. Han, J.; Remete, A. M.; Dobson, L. S.; Kiss, L.; Izawa, K.; Moriwaki, H.; Soloshonok, V. A.; O'Hagan, D., Next generation organofluorine containing blockbuster drugs. J. Fluorine Chem. 2020, 239, 109639.

8. Park, B. K.; Kitteringham, N. R.; O'Neill, P. M., Metabolism of Fluorine-Containing Drugs. Annu. Rev. Pharmacool. Toxicol. 2001 , 41, 443-470.

9. O'Neill, P. M.; Harrison, A. C.; Storr, R. C.; Hawley, S. R.; Ward, S. A.; Park, B. K., The Effect of Fluorine Substitution on the Metabolism and Antimalarial Activity of Amodiaquine. J. Med. Chem. 1994, 37, 1362-1370.

10. Arnott, J. A.; Planey, S. L., The influence of lipophilicity in drug discovery and design. Expert Opin. Drug Discov. 2012, 7, 863-875.

11. Gleeson, M. P.; Hersey, A.; Montanari, D.; Overington, J., Probing the links between in vitro potency, ADMET and physicochemical parameters. Nat. Rev. Drug Discov. 2011, 10, 197-208.

12. Johnson, T. W.; Gallego, R. A.; Edwards, M. P., Lipophilic Efficiency as an Important Metric in Drug Design. J. Med. Chem. 2018, 61, 6401-6420.

13. Waring, M. J., Lipophilicity in drug discovery. Expert Opin. Drug Discov. 2010, 5, 235-248.

14. Linclau, B.; Wang, Z.; Compain, G.; Paumelle, V.; Fontenelle, C. Q.; Wells, N.; Weymouth-Wilson, A., Investigating the Influence of (Deoxy)fluorination on the Lipophilicity of NonUV-Active Fluorinated Alkanols and Carbohydrates by a New $\log \mathrm{P}$ Determination Method. Angew. Chem. Int. Ed. 2016, 55, 674-678.

15. Jeffries, B.; Wang, Z.; Graton, J.; Holland, S. D.; Brind, T.; Greenwood, R. D. R.; Le Questel, J.-Y.; Scott, J. S.; Chiarparin, E.; Linclau, B., Reducing the Lipophilicity of Perfluoroalkyl Groups by CF2-F/CF2-Me or CF3/CH3 Exchange. J. Med. Chem. 2018, 61, 10602-10618.

16. Jeffries, B.; Wang, Z.; Felstead, H. R.; Le Questel, J.-Y.; Scott, J. S.; Chiarparin, E.; Graton, J.; Linclau, B., Systematic Investigation of Lipophilicity Modulation by Aliphatic Fluorination Motifs. J. Med. Chem. 2020, 63, 1002-1031.

17. Troup, R. I.; Jeffries, B.; Saudain, R. E.-B.; Georgiou, E.; Fish, J.; Scott, J. S.; Chiarparin, E.; Fallan, C.; Linclau, B., Skipped Fluorination Motifs: Synthesis of Building Blocks and Comparison of Lipophilicity Trends with Vicinal and Isolated Fluorination Motifs. The Journal of Organic Chemistry 2021, 86, 1882-1900.

18. Rodil, A.; Bosisio, S.; Ayoup, M. S.; Quinn, L.; Cordes, D. B.; Slawin, A. M. Z.; Murphy, C. D.; Michel, J.; O'Hagan, D., Metabolism and hydrophilicity of the polarised 'Janus face' all-cis tetrafluorocyclohexyl ring, a candidate motif for drug discovery. Chem, Sci. 2018, 9, 3023-3028.

19. Tomita, R.; Al-Maharik, N.; Rodil, A.; Bühl, M.; O'Hagan, D., Synthesis of aryl $\alpha, \alpha$-difluoroethyl thioethers a novel structure motif in organic chemistry, and extending to aryl $\alpha, \alpha$-difluoro oxyethers. Org. Biomol. Chem. 2018, 16, 1113-1117.

20. Fang, Z.; Cordes, D. B.; Slawin, A. M. Z.; O'Hagan, D., Fluorine containing cyclopropanes: synthesis of aryl substituted all-cis 1,2,3-trifluorocyclopropanes, a facially polar motif. Chem. Commun. 2019, 55, 10539-10542.

21. Huchet, Q. A.; Kuhn, B.; Wagner, B.; Fischer, H.; Kansy, M.; Zimmerli, D.; Carreira, E. M.; Müller, K., On the polarity of partially fluorinated methyl groups. J. Fluorine Chem. 2013, 152, 119-128.

22. Huchet, Q. A.; Kuhn, B.; Wagner, B.; Kratochwil, N. A.; Fischer, H.; Kansy, M.; Zimmerli, D.; Carreira, E. M.; Müller, K., Fluorination Patterning: A Study of Structural Motifs That Impact Physicochemical Properties of Relevance to Drug Discovery. J. Med. Chem. 2015, 58, 9041-9060.
23. Vorberg, R.; Trapp, N.; Zimmerli, D.; Wagner, B.; Fischer, H.; Kratochwil, N. A.; Kansy, M.; Carreira, E. M.; Müller, K., Effect of Partially Fluorinated N-Alkyl-Substituted Piperidine-2carboxamides on Pharmacologically Relevant Properties. ChemMedChem 2016, 11, 2216-2239.

24. Huchet, Q. A.; Trapp, N.; Kuhn, B.; Wagner, B.; Fischer, H.; Kratochwil, N. A.; Carreira, E. M.; Müller, K., Partially fluorinated alkoxy groups - Conformational adaptors to changing environments. J. Fluorine Chem. 2017, 198, 34-46.

25. Fox, M. A.; Pattison, G.; Sandford, G.; Batsanov, A. S., $19 \mathrm{~F}$ and 13C GIAO-NMR chemical shifts for the identification of perfluoro-quinoline and -isoquinoline derivatives. J. Fluorine Chem. 2013, 155, 62-71.

26. Pattison, G., Fluorination of organoboron compounds. Org. Biomol. Chem. 2019, 17, 5651-5660.

27. Pattison, G.; Sandford, G.; Wilson, I.; Yufit, D. S.; Howard, J. A. K.; Christopher, J. A.; Miller, D. D., Polysubstituted and ringfused pyridazine systems from tetrafluoropyridazine. Tetrahedron 2017, 73, 437-454.

28. Pattison, G.; Sandford, G.; Yufit, D. S.; Howard, J. A. K.; Christopher, J. A.; Miller, D. D., N-Functionalised polyfluoropyridazin-3(2H)-one derivatives. Tetrahedron 2009, 65, 8844-8850.

29. Pattison, G.; Sandford, G.; Yufit, D. S.; Howard, J. A. K.; Christopher, J. A.; Miller, D. D., 9,10-Dioxa-1,2-diaza-anthracene derivatives from tetrafluoropyridazine. Beilstein J. Org. Chem. 2010, 6, 45.

30. Pinfold, H.; Greenland, C.; Pattison, G.; Costantini, G., Fluorinated carboxylic acids as powerful building blocks for the formation of bimolecular monolayers. Chem. Commun. 2020, 56, 125-128.

31. Pinfold, H.; Pattison, G.; Costantini, G., Fluorination as a route towards unlocking the hydrogen bond donor ability of phenolic compounds in self-assembled monolayers. CrystEngComm 2020, 22, 2425-2428.

32. Dossetter, A. G.; Griffen, E. J.; Leach, A. G., Matched Molecular Pair Analysis in drug discovery. Drug Discov. Today 2013, 18, 724-731.

33. Wassermann, A. M.; Bajorath, J., Large-scale exploration of bioisosteric replacements on the basis of matched molecular pairs. Future Med. Chem. 2011, 3, 425-436.

34. Griffen, E.; Leach, A. G.; Robb, G. R.; Warner, D. J., Matched Molecular Pairs as a Medicinal Chemistry Tool. J. Med. Chem. 2011, 54, 7739-7750.

35. Papadatos, G.; Alkarouri, M.; Gillet, V. J.; Willett, P.; Kadirkamanathan, V.; Luscombe, C. N.; Bravi, G.; Richmond, N. J.; Pickett, S. D.; Hussain, J.; Pritchard, J. M.; Cooper, A. W. J.; Macdonald, S. J. F., Lead Optimization Using Matched Molecular Pairs: Inclusion of Contextual Information for Enhanced Prediction of hERG Inhibition, Solubility, and Lipophilicity. J. Chem. Inf. Model. 2010, 50, 1872-1886.

36. Sangster, J., Octanol-Water Partition Coefficients of Simple Organic Compounds. J. Phys. Chem. Ref. Data 1989, 18, 1111-1229.

37. C. Hansch; A. Leo; Hoekman, D., In Exploring QSAR Hydrophobic, Electronic, and Steric Constants, American Chemical Society,: Washington, DC, 1995.

38. von der Ohe, P. C.; Kühne, R.; Ebert, R.-U.; Altenburger, R.; Liess, M.; Schüürmann, G., Structural Alerts - A New Classification Model to Discriminate Excess Toxicity from Narcotic Effect Levels of Organic Compounds in the Acute Daphnid Assay. Chem. Res. Toxicol. 2005, 18, 536-555.

39. Du, C. M.; Valko, K.; Bevan, C.; Reynolds, D.; Abraham, M. H., Rapid Gradient RP-HPLC Method for Lipophilicity Determination: A Solvation Equation Based Comparison with Isocratic Methods. Anal. Chem. 1998, 70, 4228-4234.

40. Terada, H., Determination of Log Poct by High-Performance Liquid Chromatography, and its Application in the Study of Quantitative Structure-Activity Relationships. Quant. Struct.-Act. Relat. 1986, 5, 81-88. 
41. Howard, J. A. K.; Hoy, V. J.; O'Hagan, D.; Smith, G. T., How good is fluorine as a hydrogen bond acceptor? Tetrahedron 1996, $52,12613-12622$.

42. Dunitz, J. D.; Taylor, R., Organic Fluorine Hardly Ever Accepts Hydrogen Bonds. Chem. Eur. J. 1997, 3, 89-98.

43. O'Hagan, D., Understanding organofluorine chemistry. An introduction to the C-F bond. Chem. Soc. Rev. 2008, 37, 308-319.

44. Schneider, H.-J., Hydrogen bonds with fluorine. Studies in solution, in gas phase and by computations, conflicting conclusions from crystallographic analyses. Chem, Sci. 2012, 3, 1381-1394.

45. Panini, P.; Chopra, D., Experimental and Theoretical Characterization of Short H-Bonds with Organic Fluorine in Molecular Crystals. Cryst. Growth Des. 2014, 14, 3155-3168.

46. Struble, M. D.; Kelly, C.; Siegler, M. A.; Lectka, T., Search for a Strong, Virtually "No-Shift" Hydrogen Bond: A Cage Molecule with an Exceptional $\mathrm{OH} \cdots \mathrm{F}$ Interaction. Angew. Chem. Int. Ed. 2014, 53, 8924-8928.

47. Champagne, P. A.; Desroches, J.; Paquin, J.-F., Organic Fluorine as a Hydrogen-Bond Acceptor: Recent Examples and Applications. Synthesis 2015, 47, 306-322.

48. Taylor, R., The hydrogen bond between N-H or $\mathrm{O}-\mathrm{H}$ and organic fluorine: favourable yes, competitive no. Acta Crystallogr. B Struct. Sci. Cryst. 2017, 73, 474-488.

49. Abraham, M. H.; Chadha, H. S.; Whiting, G. S.; Mitchell, R. C., Hydrogen bonding. 32. An analysis of water-octanol and wateralkane partitioning and the $\Delta \log \mathrm{p}$ parameter of seiler. J. Pharm. Sci. 1994, 83, 1085-1100.

50. Chopra, D., Is Organic Fluorine Really "Not" Polarizable? Cryst. Growth Des. 2012, 12, 541-546.

51. Kuhn, B.; Mohr, P.; Stahl, M., Intramolecular Hydrogen Bonding in Medicinal Chemistry. J. Med. Chem. 2010, 53, 26012611.

52. Chen, D.; Zhao, M.; Tan, W.; Li, Y.; Li, X.; Li, Y.; Fan, X., Effects of intramolecular hydrogen bonds on lipophilicity. Eur. J. Pharm. Sci. 2019, 130, 100-106.

53. THIAZOLES AS FUNGICIDES. US2009/30024, 2009.

54. Shrivastava, S. K.; Patel, B. K.; Tripathi, P. N.; Srivastava, P.; Sharma, P.; Tripathi, A.; Seth, A.; Tripathi, M. K., Synthesis, evaluation and docking studies of some 4-thiazolone derivatives as effective lipoxygenase inhibitors. Chem. Pap. 2018, 72, 2769 2783.

55. Amir, M.; Asif, S.; Ali, I.; Hassan, M. Z., Synthesis of benzothiazole derivatives having acetamido and carbothioamido pharmacophore as anticonvulsant agents. Med. Chem. Res. 2012, 21, 2661-2670.

56. Austin, R. P.; Barton, P.; Bonnert, R. V.; Brown, R. C.; Cage, P. A.; Cheshire, D. R.; Davis, A. M.; Dougall, I. G.; Ince, F.; Pairaudeau, G.; Young, A., QSAR and the Rational Design of LongActing Dual D2-Receptor/ $\beta 2$-Adrenoceptor Agonists. J. Med. Chem. 2003, 46, 3210-3220.

57. Seiler; Zimmermann, 5-Phenyl-1,3-dihydro-1,4benzodiazepin-2-ones. Experimental verification of substituent constants. Arzneim.-Forsch. 1983, 33, 1519 - 1522.

58. Kabankin, A. S.; Boldeskul, I. E.; Trinus, F. P.; Protsenko, L. D.; Landau, M. A., Physicochemical characteristics, antineoplastic activity, and quantitative aspects of the relationship of structure and biological activity for benzoyldiethylenetriamides of phosphoric acid. Pharm. Chem. J. 1982, 16, 626-632.

59. Jarry; Dubost; Pehourcq, Comparison of lipophilic parameters in a series of 5-(115-aryl-4-piperanzinyl)methyl-2amino-2-oxazolines. Pharm. Sci. 1997, 3, 213 - 216.

60. de Candia, M.; Fossa, P.; Cellamare, S.; Mosti, L.; Carotti, A.; Altomare, C., Insights into structure-activity relationships from lipophilicity profiles of pyridin- $2(1 \mathrm{H})$-one analogs of the cardiotonic agent milrinone. Eur. J. Pharm. Sci. 2005, 26, 78-86.

61. Sylvester-Hvid, K. O.; Åstrand, P.-0.; Ratner, M. A.; Mikkelsen, K. V., Frequency-Dependent Molecular Polarizability and Refractive Index: Are Substituent Contributions Additive? J. Phys. Chem. A. 1999, 103, 1818-1821.

62. Tetko, I. V.; Tanchuk, V. Y.; Villa, A. E. P., Prediction of nOctanol/Water Partition Coefficients from PHYSPROP Database Using Artificial Neural Networks and E-State Indices. J. Chem. Inform. Comput. Sci. 2001, 41, 1407-1421.

63. Tetko, I. V.; Tanchuk, V. Y., Application of Associative Neural Networks for Prediction of Lipophilicity in ALOGPS 2.1 Program. J. Chem. Inform. Comput. Sci. 2002, 42, 1136-1145.

64. Tetko, I. V.; Poda, G. I., Application of ALOGPS 2.1 to Predict $\log$ D Distribution Coefficient for Pfizer Proprietary Compounds. J. Med. Chem. 2004, 47, 5601-5604. 